\title{
Brief Analysis on the Teaching Reform of Java Course under the New Employment Situation
}

\author{
Liang Cao \\ Jiangxi Vocation College of Ahead Software, China
}

Keywords: Java, Classroom teaching, Teaching reform

\begin{abstract}
Under the new employment situation, how to ensure the seamless connection between teaching and enterprise needs is an urgent problem to be solved in the process of current teaching. Based on the actual teaching work, this paper puts forward some reasonable teaching reform measures and obtains good teaching effect through analyzing the current teaching situation of Java language programming.

Java language programming is an integrated programming system and application architecture, widely used in smart card, hand-held electronic consumer products, desktop applications, enterprise applications, and other fields, the current hot Android platform application is written by a powerful Java language. The software development market has always had a large demand gap for Java programmers. In order to meet the requirement of the current job market, the computer major in most colleges and universities set up related courses in the Java system, the teaching of Java language programming has become an important branch of computer programming teaching in universities and colleges in China.

Although colleges and universities have set up related Java courses with different degrees, most computer professional students lack of practical ability, practical skills and experience, there is a big gap between the actual needs of the enterprise, which is difficult for enterprises to recruit qualified Java developers to meet the needs from the graduates. The paradox of "employment difficulty and labor shortage" prompts us to reflect on the current situation and shortcomings of classroom teaching in colleges and universities. How to reform the classroom teaching for new business development situation, really improve the students' practical development ability, to make students better able to meet the needs of employment, to become a hot spot of research and discussion in Java teaching in colleges and universities.
\end{abstract}

\section{Analysis on the current situation of Java teaching in colleges and universities}

\subsection{The application architecture is incomplete}

Most colleges and universities are limited by the time of class, mainly teach the basic part of the J2SE which is the most basic part in Java language system, and for the subsequent JavaWeb, JavaEE are not set up or partially set up, leading to unable to systematically and coherently consolidate the ability of students' programming development in the follow-up course, student's learning systemic is poorer, which is difficult to stimulate student's interest in learning.

\subsection{The content of teaching is lagging behind}

In order to meet the requirements of enterprise's efficient and practical code development, new theories, methods and frameworks have been introduced into the Java system, and are also used by enterprises. Compared with the rapid development of technology in the industry, colleges and universities are lagging behind in terms of teaching content, can't keep up with the pace of enterprise technology development, which caused the disconnect between the development technology of enterprise and the teaching content in colleagues and universities. 


\subsection{The experiment is divorced from the teaching link}

The Java course has its own uniqueness, such as abstract theoretical knowledge, rigorous logicality, more concept, relatively complex frame and structure, etc. Many colleges and universities are still a classroom teaching method that use the traditional programming language, emphasis on basic theoretical knowledge, spread and stack a wide range of grammatical knowledge points, the teaching content lacks some practical links related to the programming, lack of training for students' necessary programming ability.

This kind of traditional teaching pattern for programming language makes students study in a passive position, it is difficult to help students learn the essence of Java, and it is not conducive to students' understanding of basic theoretical knowledge and the exercise of basic skills in programming.

\subsection{Ignore the cultivation of students' self-learning ability}

In the process of learning Java, a lot of students are limited to the basic level, such as reading books, listening to lectures, don't want to start work before sitting in computer for programming, or are in awe of programming, dare not debug the Bug, encounter problems directly consult teachers, teachers tend to be directly told the students the correct answer. This passive learning ways although for teachers and students are easy, but for a long time, students will lose their ability to think and solve problems independently, the enthusiasm and initiative of learning are also very poor, it is impossible to achieve a combination of learning.

\section{Measures and Suggestions for improving Java classroom teaching}

\subsection{Design a reasonable and scientific course content and construct a complete knowledge system and framework}

In terms of course system construction, Java as an introductory language, a basic application architecture, and a development platform for object-oriented programming, around this framework, to set up the corresponding course system from the perspective of application. We take the "understanding, programming, using" as the teaching goal, take the Java language as the basis and the main line, combined with subsequent course JavaEE, JavaME, to set up a complete course knowledge system, so as to guarantee the continuous line of "learning and using", to enable students to master a complete knowledge structure and professional skills in an application direction. In this way, students can fully understand the status, role and value of the course in the knowledge system, and clear the learning goals and main directions.

In terms of teaching content, following up the changes in Java technology development and software development market for talent demand, introducing the new theory of the subject frontier and the new technology of the industry into the classroom teaching, and integrating the software engineering ideas, object-oriented basic principles, application cases, and new development tool platforms together, can make our teaching content to keep up with the development of technology, also can let students learn more new technology and new knowledge, to enhance students' learning purpose.

\subsection{Use heuristic classroom teaching method to improve students' interest in learning}

In the course of teaching, change the teaching model of teachers teaching and students listening, adopt heuristic teaching instead of the traditional cramming teaching, according to the thinking process and cognitive law for students to grasp the knowledge, to set up the corresponding question, to inspire students' active thinking, in the form of interactive teaching, to help students to learn knowledge in active learning knowledge and relaxed classroom atmosphere.

For example, in Java teaching, we can ask students to analyze the process of "making tea" with two different programming ideas. If we use the process-oriented thinking to analyze, the steps are as follows: prepare cold water, boil water, prepare tea sets, and pour boiling water. However, if we use the object-oriented thinking to analyze, we first extract the objects in the whole problem domain, 
the water bottles, tea sets and tea leaves, the corresponding classes are extracted from these three objects. Guide students to understand "what is a class? What attribute variables and methods should be included in the class? What is the relationship between classes? What is an object?" and other concepts. Then we can further expand the scope of the problem, to analyze the advantages and disadvantages of these two ideas, and to let the students accept and establish the object oriented thoughts from the subjective perspective. For some boring theoretical concepts, try to illustrate through some superficial metaphors. So it can translate the abstract and boring theoretical knowledge scientifically and effectively into vivid and interesting examples, it is more easy for students to understand and absorb, to improve the effect of classroom teaching, and the increase of interest is also beneficial to the improvement of students' interest in learning.

\subsection{Adopt the practice teaching method of "reading-programming-revising" to cultivate students' programming ability}

In the practice teaching, for students who have no prior experience related programming, do not know how to start for initial programming, it is necessary to develop students' correct programming thinking step by step in the course of teaching, can adopt the teaching method of "reading programming - revising".

First, guide the students to "read the code". For each knowledge point to explain a large number of exercises, to guide and encourage students to read some excellent source code. Through reading examples, students deepen their understanding of grammar and program structure, broaden their vision of programming, and develop good programming style and thinking habits.

Second, instruct students to "write the code". On the basis of the example, change the condition or similar topic, to encourage the student to imitate the example to write the code to implement. Even if students sometimes don't understand the code they are knocking on, they can run first, see the results, and rise to a rational understanding by increasing perceptual knowledge.

Finally, train the students to "revise the code". In this process, develop the students' ability of error checking and error correction as the starting point and the foothold, if students encountered problems in the process of encoding, teach students the basic ability of error correction and error debuging, guide students how to apply what they learned from the API and online for answers, find out the reason and solution for the error occurred. Encourage students to solve problems by themselves, let students read programs to each other, find and correct the errors, and when they communicate with each other, they will also inspire and motivate each other to learn from each other. This can stimulate students' learning initiative and participation, to make the students really involved in the process of the programming and debugging the errors, to digest and master the knowledge in actual coding and solving errors, cultivate the habit of active thinking and autonomous learning, to improve the ability of programming and debugging, but also cultivate their ability of solidarity and collaboration.

\subsection{Set up the link of innovative experiments and training, and organize the course design}

Carefully split and arrange the actual case of the enterprise, design the subjects with reasonable level and difficulty and different skills, send a task ahead of time and arrange an analysis of a similar case, targetlly help junior students for system design and coding.

For senior students, we split up the commercialization project developed by the advanced technology, and carefully develop a rigorous and reasonable practical training course. Select teachers who have strong hands-on skills and rich experience in project development as training teachers, to lead the students to do technical analysis and system design, and to guide students to

achieve the project tasks. This can effectively improve the students' comprehensive application ability of knowledge and shorten the employment adjustment period.

\subsection{Effectively use the network teaching environment to build integrated teaching resource database}

Through the establishment of Java high quality course website, to set up a platform for supporting network teaching and rich three-dimensional teaching resources, to provide students the 
channels of learning after class and online, and publish the teaching resources with rich graphic audio-visual on the Internet, such as electronic lesson plans, multimedia teaching courseware, teaching outline, experiment outline, experiment instructions, detailed knowledge point requirements, homework, teaching cases, e-book, teaching video, experimental requirements and so on. Set up learning forum and FAQ, make it a platform to conduct synchronous and asynchronous tutoring and discuss hot issues between teachers and students, students and students. Provide simulation test questions, to let the students understand their knowledge mastery, and cultivate the students' self-learning ability.

\subsection{Reform the form of course examination, stimulate the student to learn the fighting spirit}

The course examination link is the source of students' learning pressure and motivation. The Java course is more practical, the past paper test is difficult to reflect the students' actual language proficiency and hands-on ability. Therefore, we have developed a set of examination system, which can be randomly selected from the question bank, and students must use the computer to answer questions and program on the Internet. This way of examination can maximally avoid copying each other between the students, let students have more pressure and motive force, force them to exercise programming ability, do the integration of teaching and examination, and the interaction of teaching.

The reform of above teaching content, teaching means and teaching method integrates the heuristic teaching, case teaching, task driven teaching, discussion teaching, and a variety of teaching methods, in the teaching practice of "Java language program design" in our school, has achieved a good teaching effect, students' study enthusiasm, hand-on ability, ability to solve practical problems, and competitiveness have been significantly enhanced.

\section{References}

[1] Chaoyu Yang. Research and exploration on teaching methods of Java programming courses [J]. Computer knowledge and technology, 2009, (5).

[2] Xinyan Yang, Hongtao Liang. Research on Java language teaching in independent undergraduate colleges [J]. Discipline construction and teaching reform, 2009, (12).

[3] Hong Liu, Jiuke Song. Analysis on the teaching reform of JAVA language programming [J]. Education and occupation, 2013, (3).

[4] Xuejiao Yu. Discussion on the teaching reform of Java [J]. Information technology and informatization, 2015, (3). 